\title{
In Vitro Assessment of Artificial Aging on the Antifungal Activity of PMMA Denture Base Material Modified with $\mathrm{ZrO}_{2}$ Nanoparticles
}

\author{
Shorouq Khalid Hamid $\left(\mathbb{D},{ }^{1}\right.$ Lujain Ali Alghamdi $\mathbb{D D}^{1}$, Faris A. Alshahrani $\mathbb{D D}^{2}$ \\ Soban Q. Khan $\mathbb{D}^{3},{ }^{3}$ Asif Matin $\mathbb{D}^{4},{ }^{4}$ and Mohammed M. Gad $\mathbb{D D}^{2}$ \\ ${ }^{1}$ College of Dentistry, Imam Abdulrahman Bin Faisal University, P.O. Box 1982, Dammam 41441, Saudi Arabia \\ ${ }^{2}$ Department of Substitutive Dental Sciences, College of Dentistry, Imam Abdulrahman Bin Faisal University, P.O. Box 1982, \\ Dammam 41441, Saudi Arabia \\ ${ }^{3}$ Department of Dental Education, College of Dentistry, Imam Abdulrahman Bin Faisal University, P.O. Box 1982, \\ Dammam 41441, Saudi Arabia

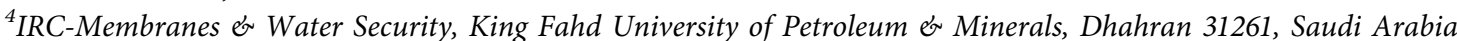

Correspondence should be addressed to Shorouq Khalid Hamid; 2140007660@iau.edu.sa

Received 19 February 2021; Revised 26 April 2021; Accepted 30 April 2021; Published 13 May 2021

Academic Editor: Stefano Pagano

Copyright ( $\odot 2021$ Shorouq Khalid Hamid et al. This is an open access article distributed under the Creative Commons Attribution License, which permits unrestricted use, distribution, and reproduction in any medium, provided the original work is properly cited.

\begin{abstract}
The antifungal effect of zirconium dioxide nanoparticles $\left(\mathrm{ZrO}_{2} \mathrm{NPs}\right)$ incorporated into denture base material has been inadequately investigated; additionally, to the authors' knowledge, no studies have assessed the influence of artificial aging on the antifungal activity of these particles. Methodology. Heat-polymerized acrylic resin disks were fabricated and divided into four groups $\left(0 \%, 1 \%, 2.5 \%\right.$, and $5 \% \mathrm{ZrO}_{2} \mathrm{NPs}$ by weight). Antifungal activity was assessed using the direct culture and disk diffusion methods. Surface roughness and contact angles were measured using a profilometer and a goniometer, respectively. The artificial aging procedure was performed by repeating all tests at 7, 14, and 30 days following 2 rounds of thermocycling. Data were analyzed using ANOVA and Tukey's post-hoc test $(p<0.05)$. Results. The addition of $\mathrm{ZrO}_{2} \mathrm{NPs}$ significantly decreased the adhesion of Candida albicans with and without artificial aging procedures $(p<0.001)$, while the disk diffusion methods did not reveal inhibition zones. $\mathrm{ZrO}_{2} \mathrm{NP}$-modified specimens displayed significantly higher surface roughness compared to specimens in the control group $(p<0.05)$ and showed the same behaviors with artificial aging procedures. The contact angle was significantly decreased in all modified groups in comparison to the control group $(p<0.05)$. Conclusion. The addition of $\mathrm{ZrO}_{2} \mathrm{NPs}$ to polymethylmethacrylate denture base material reduced the adhesion of Candida albicans with a long-term antifungal effect. With the addition of $\mathrm{ZrO}_{2} \mathrm{NPs}$, contact angles were decreased and surface roughness was increased; 1\% was the most appropriate concentration. Clinical significance. The addition of $\mathrm{ZrO}_{2} \mathrm{NPs}$ to denture base material confers a long-term antifungal effect and could be used as a possible method for preventing and treating denture stomatitis.
\end{abstract}

\section{Introduction}

Denture-induced stomatitis (DIS) is a widespread disease affecting $65 \%$ of denture wearers, with the most affected site being the palatal mucosa [1]. Several factors have been implicated in the development of DIS, including decreased salivary flow, ill-fitting dentures, poor oral hygiene, trauma to the oral mucosa, and microbial infections, primarily fungal infections with Candida albicans (C. albicans) [2]. Many studies have investigated the role of C. albicans, yielding strong evidence that it is the primary fungal source $[3,4]$. Additionally, denture base material is naturally porous, rendering its surface a favorable medium for the adherence and colonization of C. albicans [5]. Subsequently, biofilm formation occurs, which decreases cleansing efficacy and increases resistance to antifungal treatment [6]. 
Several treatment modalities have been fabricated to prevent fungal growth on denture bases, including the use of different denture cleansing agents [7] and antifungal medications [8] as well as the incorporation of antifungal agents into denture base materials [9]. However, using denture cleansing agents could cause deterioration of the denture base and lead to a rougher surface, consequently increasing susceptibility to Candida adhesion [10]. Moreover, the therapeutic failure of antifungal medications is common due to the diluent effect of saliva, the cleaning action of oral muscles, and the dependence on patient compliance [8].

Various studies have shown tremendous advances in nanomaterials. These materials have demonstrated numerous promising applications in the fields of biomedical science and nanomedicine [11] due to their excellent chemical, physical, and antifungal properties [12]. In particular, zirconium dioxide nanoparticles $\left(\mathrm{ZrO}_{2} \mathrm{NPs}\right)$ have received increasing attention for their technological and scientific features [13]. A 2018 study evaluated the effect of the incorporation of $\mathrm{ZrO}_{2} \mathrm{NPs}$ into heat-polymerized polymethylmethacrylate (PMMA) denture base material in different concentrations $\left(2.5 \%, 5 \%\right.$, and $7.5 \% \mathrm{ZrO}_{2} \mathrm{NPs}$ by weight). It was concluded that the addition of $\mathrm{ZrO}_{2} \mathrm{NPs}$ to the denture base resin material increased the tensile strength of these resins [14]. Additionally, Ahmed et al. [15] found that the incorporation of $\mathrm{ZrO}_{2} \mathrm{NPs}$ into heat-polymerized denture base material in concentrations of $1.5 \%, 3 \%, 5 \%$, and $7 \%$ by weight increased the material's flexural strength, hardness, and fracture toughness, especially at the highest concentration.

It is essential to anticipate the natural effects of aging on material properties. The wet environment and temperature fluctuation of the oral cavity further affect denture base properties [16]. Therefore, an artificial aging procedure is used to mimic oral cavity conditions by way of thermocycling; tested material is subjected to alternating extreme temperatures [17]. A total of approximately 10,000 cycles in a thermocycling machine are considered equal to 1 year of clinical use $[16,18]$.

Gowri et al. [13] assessed the antifungal activity of $\mathrm{ZrO}_{2} \mathrm{NPs}$ and found that they significantly inhibited the growth of Aspergillus niger and C. albicans strains. A 2017 study took a new approach to preventing DIS by evaluating the inhibitory effect of $\mathrm{ZrO}_{2} \mathrm{NPs}$ as an antifungal agent against $C$. albicans adhesion in heat-polymerized PMMA denture base material repaired with autopolymerized acrylic resin. That study demonstrated that $\mathrm{ZrO}_{2} \mathrm{NPs}$ had a significant inhibitory effect against $C$. albicans adhesion and that a denture base modified with $\mathrm{ZrO}_{2} \mathrm{NPs}$ could be used as a method for DIS prevention [19].

Previous studies have examined the antifungal activity of $\mathrm{ZrO}_{2} \mathrm{NPs}$, but their assessments were limited due to the absence of artificial aging procedures and the lack of surface property evaluations [13, 19]. Therefore, the antifungal effect of $\mathrm{ZrO}_{2} \mathrm{NPs}$ incorporated into denture base materials has been inadequately investigated. Additionally, to the authors' knowledge, no studies have yet evaluated the influence of artificial aging on the antifungal effects of $\mathrm{ZrO}_{2} \mathrm{NPs}$. Hence, the current study was the first to assess such effects in correlation with the surface roughness and contact angle of $\mathrm{ZrO}_{2} \mathrm{NP}$-modified PMMA denture base material.

The present study had two null hypotheses. The first was that the addition of $\mathrm{ZrO}_{2} \mathrm{NPs}$ to PMMA denture base material would have no long-term antifungal effects. The second was that the addition of $\mathrm{ZrO}_{2} \mathrm{NPs}$ to PMMA denture base material would have no effect on either surface roughness or contact angle.

\section{Materials and Methods}

2.1. Specimen Preparation. Sample size calculation showed that the necessary sample size at $80 \%$ power with a $5 \%$ level of significance and a $95 \%$ confidence interval was 160 specimens (10 per test). The specimens were distributed into 4 groups based on the concentration of $\mathrm{ZrO}_{2} \mathrm{NPs}(n=40$ for each): a control group with no additives and 3 modified groups with $1 \%, 2.5 \%$, and $5 \% \mathrm{ZrO}_{2} \mathrm{NPs}$, respectively, by weight. $\mathrm{ZrO}_{2} \mathrm{NPs}(99.9 \%<100 \mathrm{~nm}, 1314-23-4$; Shanghai Richem International Co., Ltd., Shanghai, China) were added in concentrations of $1 \%, 2.5 \%$, and $5 \%$ by weight to heat-polymerized acrylic resin powder (BMS 014 powder; BMS Dental, Capannoli, PI, Italy). In order to improve adhesion between $\mathrm{ZrO}_{2} \mathrm{NPs}$ and the acrylic resin matrix, a silane coupling agent (3-(trimethoxysilyl) propyl methacrylate) (TMSPM) (Shanghai Richem International Co., Ltd., Shanghai, China) was utilized to treat the $\mathrm{ZrO}_{2} \mathrm{NPs}$. Additionally, $0.3 \mathrm{~g}$ of TMSPM was dissolved in $100 \mathrm{~mL}$ of acetone in order to confirm that the $\mathrm{ZrO}_{2} \mathrm{NPs}$ were uniformly coated. Using a magnetic stirrer (Cimarec Digital Stirring Hotplates, SP131320-33Q; Thermo Fischer Scientific, Waltham, MA, USA), $30 \mathrm{~g}$ of $\mathrm{ZrO}_{2} \mathrm{NPs}$ was added to the TMSPM/acetone solution and stirred for 1 hour. Next, to eliminate the solvent, a rotary evaporator under a vacuum was utilized for 30 minutes at $60^{\circ} \mathrm{C}$ and $150 \mathrm{rpm}$. In order to obtain the treated $\mathrm{ZrO}_{2} \mathrm{NPs}$, samples were dried, subjected to $120^{\circ} \mathrm{C}$ for 2 hours, and then bench-cooled [19-21]. The treated $\mathrm{ZrO}_{2} \mathrm{NPs}$ were weighed using an electronic balance (S-234; Denver Instrument, Gottingen, Germany) and incorporated into a heat-polymerized acrylic resin powder and then mixed using a mortar and pestle. Subsequently, these samples were stirred for 30 minutes to ensure an even particle distribution.

Disk-shaped, heat-polymerized acrylic resin specimens with dimensions of $10 \times 2 \pm 0.1 \mathrm{~mm}$ were fabricated following the conventional method and steps for denture base fabrication in accordance with the manufacturer's instructions [16, 20, 21]. Wax specimens (Vertex Dental B. V., Soesterberg, Netherlands) were obtained using negative molds and then invested in metal flasks (61B Two Flask Compress; Handler Manufacturing) and type III dental stones (Fujirock EP; GC Corporation, Tokyo, Japan). Next, the wax was eliminated with the aid of a wax elimination machine to obtain the negative mold spaces. While the stones were still warm, the separating medium (162-800-00; Vandex Isoliermittel GmbH, Hamburg, Germany) was spread over the stones' surfaces. A water/powder ratio was 
measured and then mixed in accordance with the manufacturer's instructions. The mixture was packed at the dough stage into the previously created molds under pressure. Next, the flasks were kept in flask clamps for 1 hour and then processed using a conventional heat curing unit (KaVo Elektrotechnisches Werk $\mathrm{GmbH}$, Biberach, Germany) at $74^{\circ} \mathrm{C}$ for 8 hours, then at $100^{\circ} \mathrm{C}$ for 1 hour. Following polymerization, the flasks were cooled to room temperature and then deflasked.

After deflasking, the excess resins from the deflasked specimens were removed and finished with a tungsten carbide bur (HM 79GX-040 HP; Meisinger USA, Centennial, CO, USA) with a thin cross-cut at 18,000 rpm. Next, the specimens were polished through a coarse-grain and then a fine-grain cylindrical rubber top bur (Super Acrylic Polisher; Long Dental). Polishing occurred only on the specimens' cameo surfaces, with the intaglio surfaces remaining unpolished. The specimens' dimensions were verified using a digital caliper with an accuracy of $0.01 \mathrm{~mm}$ (Neiko 01407A Electronic Digital Caliper). Specimens were kept at $37^{\circ} \mathrm{C}$ in distilled water for 1 week. To minimize the accumulation of residual monomers, the distilled water was changed daily.

2.2. Aging Procedures. All specimens were marked numerically for standardized testing before, during, and after aging procedures. Next, baseline readings were taken for antifungal activity, surface roughness, and contact angle tests $\left(T_{0}\right)$. All specimens were subsequently water-immersed for 2 weeks, after which they were subjected to 5,000 cycles in a thermocycling machine (Thermocycler THE-1100; SD Mechatronik GmbH, Feldkirchen-Westerham, Germany) between temperatures of $5^{\circ} \mathrm{C}$ and $55^{\circ} \mathrm{C}$, with a dwell time of 30 seconds for each specimen [17]. Antifungal activity, surface roughness, and contact angle tests were then repeated $\left(\mathrm{T}_{1}\right)$. All specimens were then immersed in water for 30 days, after which they were subjected to an additional 5,000 cycles to ultimately simulate 1 year of clinical use [16]. Lastly, all tests were repeated $\left(\mathrm{T}_{2}\right)$ to assess the long-term antifungal efficacy of the treatment (Figure 1).

2.3. Candida Adherence Assay. Prior to the assessment of antifungal properties, the specimens were submerged in $70 \%$ alcohol for 20 minutes and then ultrasonically cleaned using sterilized distilled water [22]. The specimens were then immersed in artificial saliva, composed of mucin, methyl4-hydroxybenzoate, benzalkonium chloride, ethylenediaminetetraacetic acid (EDTA), $\mathrm{H}_{2} \mathrm{O}_{2}$, xylitol, peppermint oil, spearmint oil, and mineral salts (A.S. Orthana, Biofac A/S, Kastrup, Denmark), with 2,000,000 C. albicans cells (ATCC 10231) for 2 days at $37^{\circ} \mathrm{C}$. The specimens were then rinsed 3 times using phosphate-buffered saline (PBS, pH 7.2) to remove nonadherent cells. Subsequently, the specimens were inserted into sterile tubes that each contained $1 \mathrm{~mL}$ of Sabouraud dextrose broth (Acu Medica Lab Systems Ltd., Mumbai, Maharashtra, India) for 1 day. The specimens were then vortexed for 10 minutes, after which they were centrifuged for 5 minutes at 4,500 rpm. Then, the specimens were removed from the tubes, leaving the clustered pellets behind in the tubes. Lastly, the C. albicans colonies that adhered to each specimen were calculated using the direct culture test $[19,20]$.

2.4. Direct Culture Method (Colony-Forming Units, CFU). A $10 \mu \mathrm{L}$ sample was taken from each centrifuge tube. Then, the samples were serially diluted and spread onto petri dishes with Sabouraud dextrose agar (LabM, Lancashire, England), after which they were incubated for 1 day at $37^{\circ} \mathrm{C}$. The number of C. albicans colonies in every quadrant was next measured with the aid of a colony counter pen (SP Scienceware; Bel-Art Products Inc., Pequannock, NJ, USA) where noticeable growth was observed, and the final numbers of colonies were corrected for the dilution factor $[19,20]$.

\subsection{Agar Disk Diffusion and Filtration Paper Methods.} Specimens were placed on blood agar plates and incubated at room temperature for 120 minutes for the diffusion of the antifungal agents [23]. Additionally, the filtration paper disk diffusion method was performed, and the acrylic disks were immersed in distilled water for 48 hours. Drops of the emerging solution were added to the sterile filter paper disks $(10 \mathrm{~mm}$ in diameter) and then placed on the surfaces of blood agar plates [24]. Then, the disk diffusion and filtration paper plates were anaerobically incubated for 1 day at $37^{\circ} \mathrm{C}$. The presence of fungal growth inhibition zones around the disks and filtration papers was visually inspected.

2.6. Surface Roughness (Ra). To determine the surface roughness $(\mathrm{Ra})$ value, a noncontact optical interferometric profilometer (Contour GT; Bruker Nano GmbH, Berlin, Germany) was employed at a $0.01 \mathrm{~mm}$ resolution. Specimens were scanned for an approximate area of $0.43 \times 0.58 \mathrm{~mm}$ using a standard camera at $20 \times$ magnification at 5 sites of each specimen. Then, the average calculation was performed. Analysis of the obtained images was conducted by a software package (Vision64, Bruker Nano) to assess pit features and to calculate the Ra values of all specimens [20].

2.7. Contact Angle Measurement. The contact angle measurement was conducted using the sessile drop test. First, the specimens' surfaces were gently air-dried. Then, distilled water droplets were placed on the specimens' surfaces using an autopipette and a goniometer in order to standardize the volume of the droplets ( $2 \mu \mathrm{L}$ each). The contact angles were measured using an automated contact angle goniometer (DM-501; Kyowa Interface Science Co, Japan). The tangent angle to the surface of the water droplet was measured and then remeasured 4 times on various sites of each specimen. Then, the average angles were calculated, and the images were analyzed using FAMAS software (Kyowa Interface Science Co., Japan) [20].

2.8. Statistical Analysis. Data analysis was performed using IBM SPSS Statistics for Windows version 19.0 (IBM Corp., 


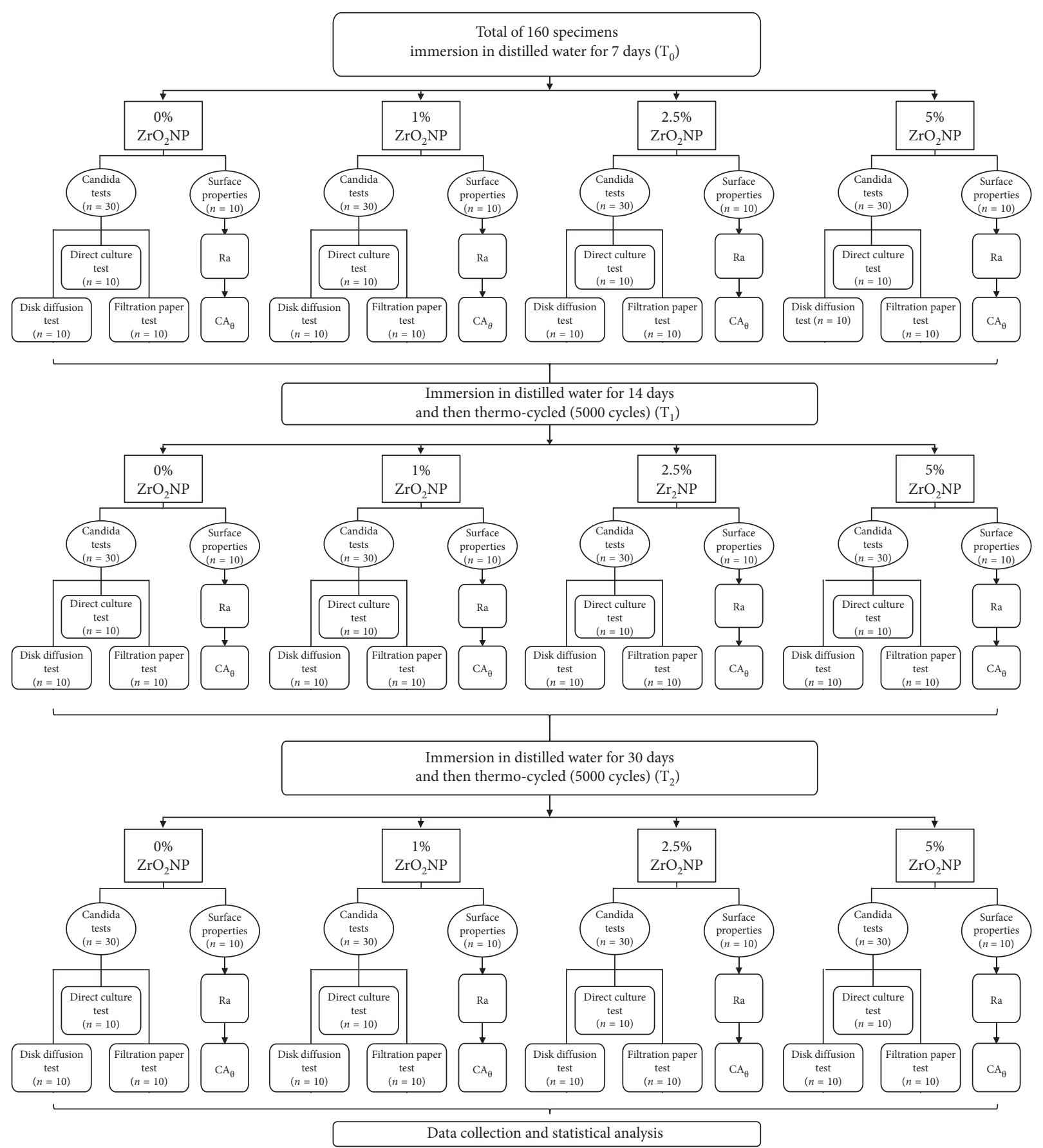

Figure 1: Flow diagram to illustrate study design. (CA) Candida adhesion; (Ra) surface roughness; $\left(\mathrm{CA}_{\theta}\right)$ contact angle; $\left(\mathrm{T}_{0}, \mathrm{~T}_{1}, \mathrm{~T}_{2}\right)$ time intervals of 7,14 , and 30 days, respectively.

Armonk, NY, USA). A Shapiro-Wilk test was performed to evaluate the normality of the data, after which parametric tests were conducted, generating significant results for the normality test. For inferential statistics, ANOVA was utilized to determine total significance in the tested variables (Candida count, $\mathrm{Ra}$, and contact angle) in comparison with time and concentration. Furthermore, Tukey's post-hoc was used for pairwise comparison. For the combined effect of time and concentration, a 2-way ANOVA was performed. A $p$ value of $\leq 0.05$ was considered statistically significant.

\section{Results}

3.1. Antifungal Activity Assessment. Results of the direct culture method showed that the $\mathrm{ZrO}_{2} \mathrm{NP}$-modified groups displayed significant antifungal effects for all tested time intervals compared to the control group $(p<0.001)$. Furthermore, the number of $C$. albicans colonies significantly decreased as the $\mathrm{ZrO}_{2} \mathrm{NP}$ concentration increased $(p<0.05)$. All of the pairwise comparisons exhibited significant differences between the means, except between the $2.5 \%$ and 
$5 \%$ groups in $\mathrm{T} 1$ (Table 1) (Figure 2). Variation across time intervals was examined for all concentrations. For the $\mathrm{ZrO}_{2} \mathrm{NP}$-modified groups, there were significant antifungal effects $(p<0.001)$ between all the time intervals except between T0 and T2 in the 1\% group and between T0 and T1 in the $5 \%$ group (Table 2). However, the disk diffusion and filtration paper methods showed negative results (absence of inhibition zones) for $\mathrm{ZrO}_{2} \mathrm{NP}$-modified groups in all the tested time intervals.

3.2. Surface Roughness (Ra). A statistically significant increase in $\mathrm{Ra}$ was found in relation to higher concentrations of $\mathrm{ZrO}_{2} \mathrm{NPs}$ added to the heat-polymerized acrylic resin compared to the control group at all time intervals $(p<0.001)$ (Table 1). The mean Ra values measured between time intervals at a given concentration were found to be statistically insignificant for the $1 \%$ and $2.5 \%$ groups $(p<0.05)$. Meanwhile, the $0 \%$ and $5 \%$ groups exhibited a significant difference $(p<0.05)$, and the pairwise comparison showed an insignificant difference only of $\mathrm{T} 1$ when compared to $\mathrm{T} 0$ and of $\mathrm{T} 2$ when compared to $\mathrm{T} 1$ in both the $0 \%$ and $5 \% \mathrm{ZrO}_{2} \mathrm{NP}$-modified groups (Table 2) (Figure 3).

3.3. Contact Angle. A significant reduction $(p<0.05)$ was found in contact angle measurement in all of the $\mathrm{ZrO}_{2} \mathrm{NP}$ modified groups in comparison to the control group at all time intervals, as shown in Table 1 and Figure 4 . In comparison to the time interval at a given concentration, all groups displayed significant differences $(p<0.05)$ except the $1 \%$ and $5 \%$ test groups (Table 2 ).

\section{Discussion}

A denture base with antifungal activity might be used as a method to prevent DIS and could help denture users who have disabilities or difficulties with appropriate denture cleaning [20]. An ideal criterion for any antimicrobial agent is that it should have long-term antimicrobial activity [25]. However, no previous studies have investigated the influence of artificial aging on the antifungal activity of heat-polymerized acrylic resin denture bases modified with $\mathrm{ZrO}_{2} \mathrm{NPs}$. Therefore, the current study aimed to investigate the influence of artificial aging on the antifungal activity of $\mathrm{ZrO}_{2} \mathrm{NPs}$ in correlation with the $\mathrm{Ra}$ and contact angle of heat-polymerized acrylic resin. The results demonstrated a significant long-term reduction in the adhesion of C. albicans in denture bases modified with $\mathrm{ZrO}_{2} \mathrm{NPs}$. Furthermore, the addition of $\mathrm{ZrO}_{2} \mathrm{NPs}$ decreased the contact angle while increasing $\mathrm{Ra}$. Therefore, the two null hypothesis of the present study (that the heat-polymerized acrylic resin modified with $\mathrm{ZrO}_{2} \mathrm{NPs}$ would have no long-term antifungal activity and no effect on $\mathrm{Ra}$ or contact angle) were rejected.

The associations between $\mathrm{ZrO}_{2} \mathrm{NP}$ concentrations and the numbers of $C$. albicans colonies demonstrated the antifungal activity of $\mathrm{ZrO}_{2} \mathrm{NPs}$, a finding consistent with those of previous studies $[13,19]$. In the present study, long-term antifungal activity was investigated by repeating all the tests at different time intervals. The results showed that a heat- polymerized acrylic resin denture base material modified with $\mathrm{ZrO}_{2} \mathrm{NPs}$ demonstrated durable antifungal activity after undergoing an artificial aging procedure that simulated 1 year of clinical use.

In the present study, the results of the direct culture method indicated a significant reduction in the number of C. albicans colonies in all $\mathrm{ZrO}_{2} \mathrm{NP}$-modified groups. The lowest number of $C$. albicans colonies was observed in the $5 \% \mathrm{ZrO}_{2} \mathrm{NP}$ group. This reduction in C. albicans colonies could be the result of the antimicrobial activity of $\mathrm{ZrO}_{2} \mathrm{NPs}$ or the enhancement of denture base surface properties [19]. Another study suggested that the antimicrobial effect of nanoparticles is due to the chemical reactivity of nanoparticle crystals that might significantly be influenced by their shape, which is affected by the arrangement of surface atoms, surface energy, and bonding [26]. Various atomic planes exhibit different surface energies, and the surface energy of nanostructures is primarily affected by the density of the dangling bonds present on their surfaces. The difference in surface energy is crucial in determining the antifungal activity of nanoparticles [27]. Furthermore, it might be presumed that $\mathrm{ZrO}_{2} \mathrm{NPs}$ have identical surface geometries, but with various shapes, several active planes could exhibit different antimicrobial effects [11]. Another explanation for the antifungal activity of $\mathrm{ZrO}_{2} \mathrm{NPs}$ is the presence of some nanoparticles on the specimens' surfaces, which might lead to direct contact between the nanoparticles and C. albicans. This could, in turn, actively prevent the growth of fungal strains by interrupting cell function, thereby deforming the fungal hyphae [13].

The results of both the conventional and filtration paper disk diffusion techniques revealed the absence of inhibition zones for all the tested concentrations of $\mathrm{ZrO}_{2} \mathrm{NPs}$. This negates the theory that the mechanism of the antifungal activity of $\mathrm{ZrO}_{2} \mathrm{NPs}$ is the leaching of nanoparticle ions. The antifungal activity of $\mathrm{ZrO}_{2} \mathrm{NPs}$ could be the result of their effect on PMMA denture base surface properties, and as such, further investigations should be conducted to confirm the antifungal mechanism of $\mathrm{ZrO}_{2} \mathrm{NPs}$.

Adhesion of $C$. albicans has been shown to directly correlate with $\mathrm{Ra}$, owing to the ability of C. albicans, in its mycelial form, to infiltrate the minuscule protrusions on the rough surface of the denture base [28]. The results of the present study revealed significant increases in Ra with higher concentrations of $\mathrm{ZrO}_{2} \mathrm{NPs}$ and exhibited the same behaviors with respect to aging procedures. However, a more than $1 \%$ addition of $\mathrm{ZrO}_{2} \mathrm{NPs}$ increased $\mathrm{Ra}$ beyond the acceptable clinical value $(0.2 \mu \mathrm{m})$ [5]. This increase might be attributable to the agglomeration and cluster formation of nanoparticles on the specimens' surfaces [29]. Also, previous studies have reported that $\mathrm{Ra}$ increases with higher concentrations of nanoparticles [29,30].

Similarly to the current study, Gad et al. [31] assessed the $\mathrm{Ra}$ of a heat-polymerized acrylic resin denture base material modified with $\mathrm{ZrO}_{2} \mathrm{NPs}$ at concentrations of $0.5 \%$, $1 \%$, 2.5\%, and $5 \%$. Their results demonstrated a significant increase in $\mathrm{Ra}$ beyond the acceptable clinical value $(0.33-0.49 \mu \mathrm{m})$ in modified groups except for the $0.5 \%$ group $(0.15 \mu \mathrm{m})$. The authors related this increase in $\mathrm{Ra}$ for higher $\mathrm{ZrO}_{2} \mathrm{NP}$ 
TABLE 1: Means, standard deviations, and $p$-values for heat-polymerized specimens modified with different concentrations of $\mathrm{ZrO}_{2} \mathrm{NPs}$ according to time.

\begin{tabular}{|c|c|c|c|c|c|c|c|}
\hline \multirow{2}{*}{ Time } & \multirow{2}{*}{ Concentration of $\mathrm{ZrO}_{2} \mathrm{NPs}(\%)$} & \multicolumn{2}{|c|}{ Candida count (CFU) } & \multicolumn{2}{|c|}{ Surface roughness $(\mu \mathrm{m})$} & \multicolumn{2}{|c|}{ Contact angle $\left({ }^{\circ}\right)$} \\
\hline & & Mean (SD) & $p$-value & Mean (SD) & $p$-value & Mean (SD) & $p$-value \\
\hline \multirow{4}{*}{$T_{0}$} & 0 & $2069.4(60.9)$ & \multirow{4}{*}{$0.000^{*}$} & $0.15(0.01)$ & & $92.98(1.1)$ & \multirow{4}{*}{$0.000^{*}$} \\
\hline & 1 & $1085.6(42.6)$ & & $0.19(0.01)$ & & $80.74(1.3)^{\mathrm{a}}$ & \\
\hline & 2.5 & $781.8(13.6)$ & & $0.23(0.01)$ & $0.000^{*}$ & $79.39(1.2)^{\mathrm{a}}$ & \\
\hline & 5 & $384.1(13.0)$ & & $0.25(0.01)$ & & $77.39(1.4)$ & \\
\hline \multirow{4}{*}{$T_{1}$} & 0 & $1971.5(17.6)$ & \multirow{4}{*}{$0.000^{*}$} & $0.16(0.01)$ & & $91.27(1.2)$ & \multirow{4}{*}{$0.000^{*}$} \\
\hline & 1 & $1429.1(36.9)$ & & $0.19(0.01)$ & & $80.15(1.5)$ & \\
\hline & 2.5 & $655.2(31.5)^{\mathrm{a}}$ & & $0.23(0.01)$ & $0.000^{*}$ & $78.41(1.4)^{\mathrm{a}}$ & \\
\hline & 5 & $379.3(20.0)^{\mathrm{a}}$ & & $0.26(0.01)$ & & $78.47(1.4)^{\mathrm{a}}$ & \\
\hline \multirow{4}{*}{$T_{2}$} & 0 & $1953.9(30.2)$ & \multirow{4}{*}{$0.000^{*}$} & $0.17(0.01)$ & & $91.29(1.1)$ & \multirow{4}{*}{$0.000^{*}$} \\
\hline & 1 & $1051.7(28.8)$ & & $0.19(0.01)$ & & $79.43(1.2)^{\mathrm{a}}$ & \\
\hline & 2.5 & $584.1(18.4)$ & & $0.23(0.01)$ & $0.000^{*}$ & $77.62(1.7)$ & \\
\hline & 5 & $317.2(10.5)$ & & $0.27(0.01)$ & & $77.87(1.5)^{\mathrm{a}}$ & \\
\hline
\end{tabular}

Variation in concentration was studied at different time intervals vertically: $\left(T_{0}, T_{1}, T_{2}\right)$ of 7,14 , and 30 days, respectively. Same alphabets showed insignificant results in pairwise comparison. ${ }^{*}(p>0.05)$ was considered statistically insignificant.

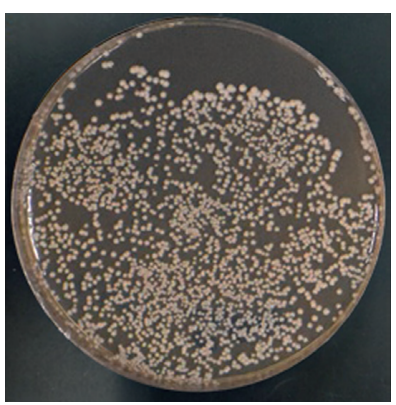

(a)

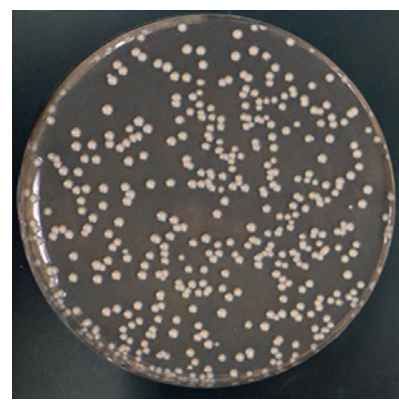

(b)

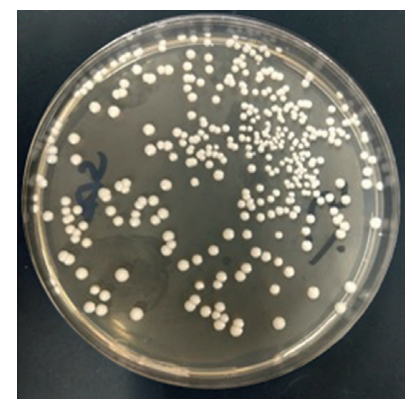

(c)

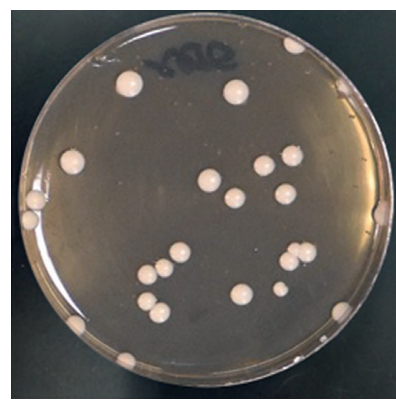

(d)

Figure 2: Direct culture method based on different $\mathrm{ZrO}_{2} \mathrm{NP}$ concentrations of heat-polymerized acrylic resin. (a) Control; (b) $1 \% \mathrm{ZrO}{ }_{2} \mathrm{NPs}$; (c) $2.5 \% \mathrm{ZrO}_{2} \mathrm{NPs}$; (d) $5 \% \mathrm{ZrO}_{2} \mathrm{NPs}$.

TABLE 2: Means, standard deviations, and $p$-values for heat-polymerized specimens modified with different concentrations of $\mathrm{ZrO}_{2} \mathrm{NPs}$ according to concentration.

\begin{tabular}{|c|c|c|c|c|c|c|c|}
\hline \multirow{2}{*}{ Concentration of $\mathrm{ZrO}_{2} \mathrm{NPs}(\%)$} & \multirow{2}{*}{ Time } & \multicolumn{2}{|c|}{ Candida count (CFU) } & \multicolumn{2}{|c|}{ Surface roughness $(\mu \mathrm{m})$} & \multicolumn{2}{|c|}{ Contact angle $\left({ }^{\circ}\right)$} \\
\hline & & Mean (SD) & $p$-value & Mean (SD) & $p$-value & Mean (SD) & $p$-value \\
\hline \multirow{3}{*}{0} & $\mathrm{~T}_{0}$ & $2069.4(60.9)$ & \multirow{3}{*}{$0.000^{*}$} & $0.15(0.01)^{\mathrm{a}}$ & \multirow{3}{*}{$0.031^{*}$} & $92.98(1.1)$ & \multirow{3}{*}{$0.003^{*}$} \\
\hline & $\mathrm{T}_{1}$ & $1971.5(17.6)^{\mathrm{a}}$ & & $0.16(0.01)^{\mathrm{a}, \mathrm{b}}$ & & $91.27(1.2)^{\mathrm{a}}$ & \\
\hline & $\mathrm{T}_{2}$ & $1953.9(30.2)^{\mathrm{a}}$ & & $0.17(0.01)^{\mathrm{b}}$ & & $91.29(1.1)^{\mathrm{a}}$ & \\
\hline \multirow{3}{*}{1} & $\mathrm{~T}_{0}$ & $1085.6(42.6)^{\mathrm{a}}$ & \multirow{3}{*}{$0.002^{*}$} & $0.19(0.01)$ & \multirow{3}{*}{0.648} & $80.74(1.3)$ & \multirow{3}{*}{0.103} \\
\hline & $\mathrm{T}_{1}$ & $1429.1(36.9)$ & & $0.19(0.01)$ & & $80.15(1.5)$ & \\
\hline & $\mathrm{T}_{2}$ & $1051.7(28.8)^{\mathrm{a}}$ & & $0.19(0.01)$ & & $79.43(1.2)$ & \\
\hline \multirow{3}{*}{2.5} & $\mathrm{~T}_{0}$ & $781.8(13.6)$ & \multirow{3}{*}{$0.000^{*}$} & $0.23(0.01)$ & & $79.39(1.2)^{\mathrm{a}}$ & \multirow{3}{*}{$0.042^{*}$} \\
\hline & $\mathrm{T}_{1}$ & $655.2(31.5)$ & & $0.23(0.01)$ & 0.258 & $78.41(1.4)^{\mathrm{a}, \mathrm{b}}$ & \\
\hline & $\mathrm{T}_{2}$ & $584.1(18.4)$ & & $0.23(0.01)$ & & $77.62(1.7)^{\mathrm{b}}$ & \\
\hline \multirow{3}{*}{5} & $\mathrm{~T}_{0}$ & $384.1(13.0)^{\mathrm{a}}$ & \multirow{3}{*}{$0.000^{*}$} & $0.25(0.01)^{\mathrm{a}}$ & & $77.39(1.4)$ & \multirow{3}{*}{0.255} \\
\hline & $\mathrm{T}_{1}$ & $379.3(20.0)^{\mathrm{a}}$ & & $0.26(0.01)^{\mathrm{a}, \mathrm{b}}$ & $0.004^{*}$ & $78.47(1.4)$ & \\
\hline & $\mathrm{T}_{2}$ & $317.2(10.5)$ & & $0.27(0.01)^{\mathrm{b}}$ & & $77.87(1.5)$ & \\
\hline
\end{tabular}

Variation in time was studied at different concentrations intervals vertically: $\left(T_{0}, T_{1}, T_{2}\right)$ of 7,14 , and 30 days, respectively. Same alphabets showed insignificant results in pairwise comparison. ${ }^{*}(p>0.05)$ was considered statistically insignificant.

concentrations to the clustering liability of nanoparticles as well as to the reduced homogeneity of the resin matrix, which was observed to be concentration-dependent. Furthermore, Lee et al. [32] found a significant increase in $\mathrm{Ra}$ with the incorporation of nanographene oxide into PMMA resin, which was mostly the result of exposed nanographene oxide on the outer surface after polishing. However, according to Fouda et al. [20], the addition of nanodiamonds 


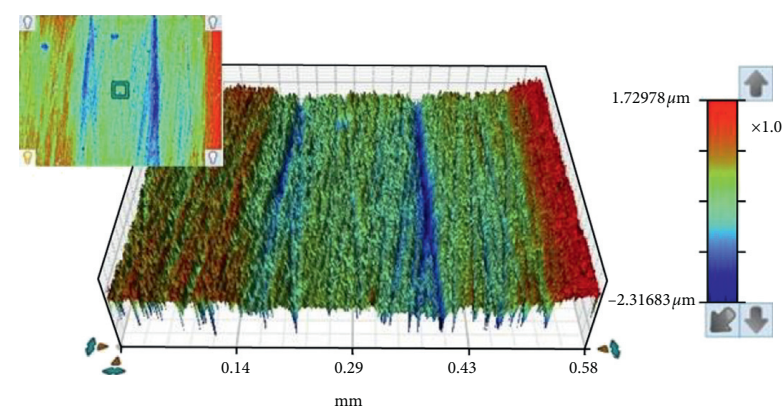

(a)

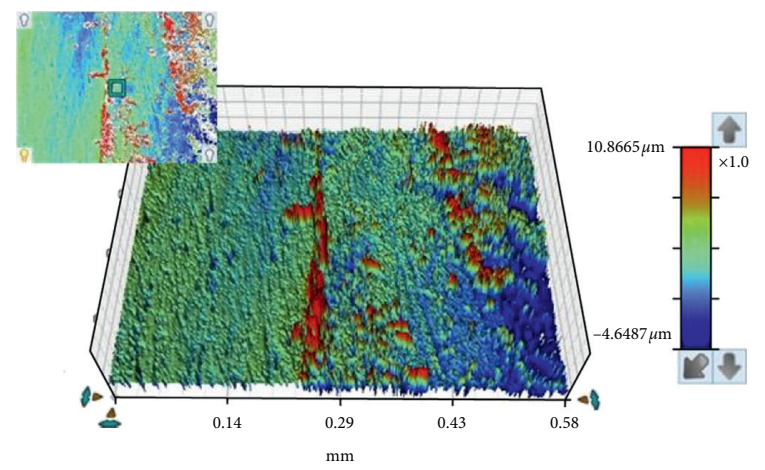

(c)

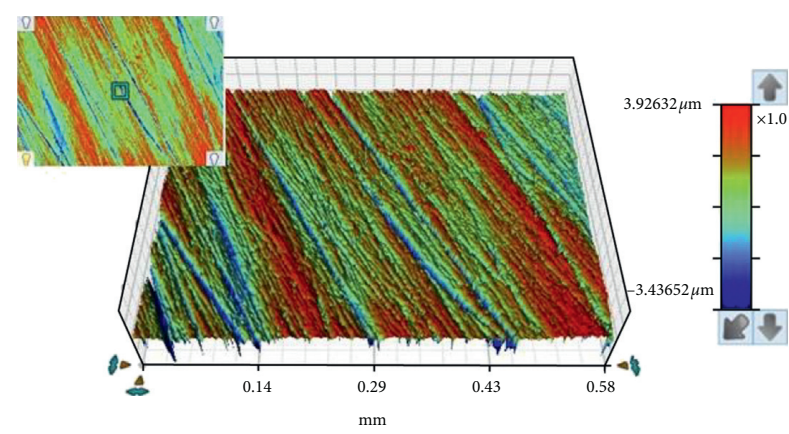

(b)

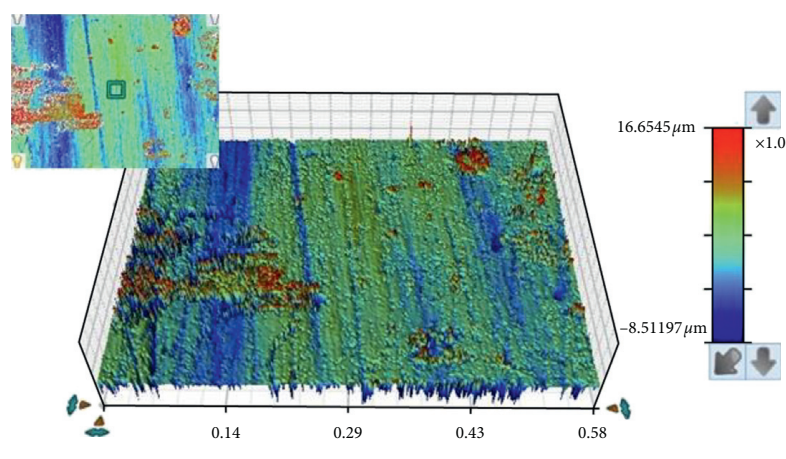

(d)

FIGURE 3: Representative surface roughness images of tested specimens based on different $\mathrm{ZrO}_{2} \mathrm{NP}$ concentrations of heat-polymerized acrylic resin. (a) Control; (b) $1 \% \mathrm{ZrO}_{2} \mathrm{NPs}$; (c) $2.5 \% \mathrm{ZrO}_{2} \mathrm{NPs}$; (d) $5 \% \mathrm{ZrO}_{2} \mathrm{NPs}$.

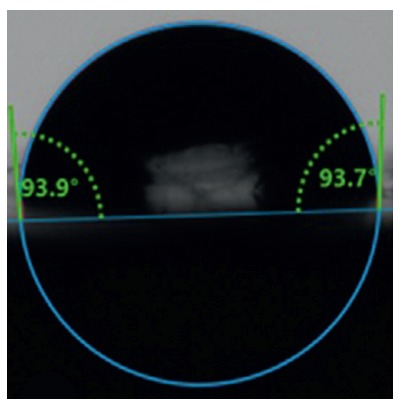

(a)

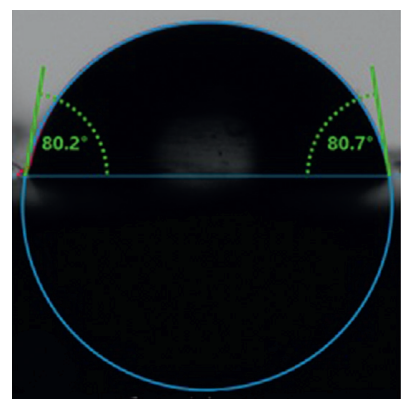

(b)

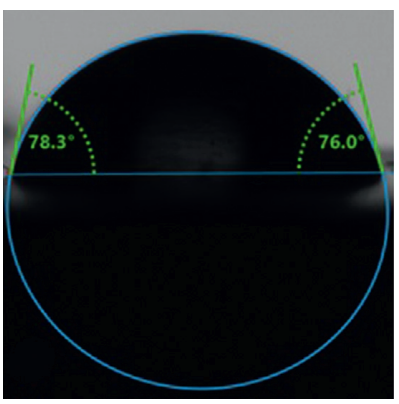

(c)

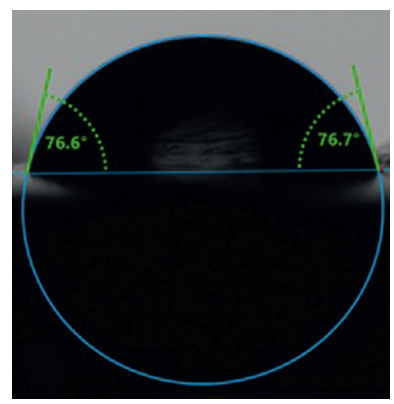

(d)

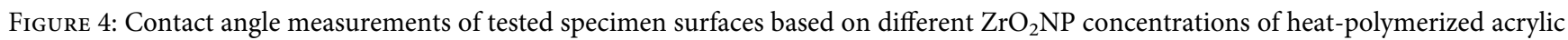
resin. (a) Control; (b) $1 \% \mathrm{ZrO}_{2} \mathrm{NPs}$; (c) $2.5 \% \mathrm{ZrO}_{2} \mathrm{NPs}$; (d) $5 \% \mathrm{ZrO}_{2} \mathrm{NPs}$

in concentrations of $0.5 \%, 1 \%$, and $1.5 \%$ to a heat-polymerized acrylic resin denture base material decreased Ra. This might be attributable to the small size of the particles, which decreases the interparticle distance, leading to proximate contact between the nanoparticles at lower concentrations.

One of the major factors affecting the adhesion of C. albicans is surface hydrophobicity. The cell surface of C. albicans is hydrophobic in nature, especially in its hyphal form, which improves its adherence to hydrophobic acrylic surfaces through the hydrophobic interaction [33]. Hydrophobic interactions occur between the cell surface and the substratum, which allows the cell to overcome the repulsive forces active within a specific distance from the substratum surface, although this depends on the surface hydrophobicity of the microbes [34]. Therefore, increasing surface hydrophilicity would represent an effective method for decreasing C. albicans adhesion [35].

According to the results of the present study, $\mathrm{ZrO}_{2} \mathrm{NP}$ modification yielded a significant decrease in contact angle. This reduction, in turn, indicates an increase in surface hydrophilicity. This finding might be explained by the interaction between $\mathrm{H}_{2} \mathrm{O}$ and $\mathrm{ZrO}_{2} \mathrm{NPs}$, which culminates in both molecular and dissociative adsorption of water [35], forming several polar interactions and, consequently, hydrophilic hydroxyl $(-\mathrm{OH})$ species on the surfaces of the particles [36]. According to Lee et al. [32], the addition of nanographene oxide to PMMA increases surface hydrophilicity due to its 
ability to create a hydration layer on the surface and produce a tightly bound water layer that represents a physical barrier to prevent adhesion of C. albicans.

Although $\mathrm{Ra}$ increased with $\mathrm{ZrO}_{2} \mathrm{NP}$ addition in the present study, numbers of $C$. albicans significantly decreased, confirming the strong antifungal effect of $\mathrm{ZrO}_{2} \mathrm{NPs}$. On the other hand, this effect could be the result of surface changes from decreasing the contact angle, thus increasing surface hydrophilicity and hence reducing $C$. albicans adhesion. Additionally, $\mathrm{ZrO}_{2} \mathrm{NPs}$ enhance the mechanical performance of PMMA denture base materials [14,15]. Clinically, $\mathrm{ZrO}_{2} \mathrm{NPs}$ can be incorporated into PMMA due to its durability with respect to decreasing the adhesion of C. albicans. The durability of the antifungal activity of the heat-polymerized acrylic resin denture base material modified with $\mathrm{ZrO}_{2} \mathrm{NPs}$ would promote denture hygiene, particularly among patients with physical disabilities. Additional studies should be conducted to evaluate the mechanism of the antifungal activity of $\mathrm{ZrO}_{2} \mathrm{NPs}$.

One strength of the present study was that it applied 3 techniques for assessing the long-term antifungal activity of heat-polymerized acrylic resin modified with $\mathrm{ZrO}_{2} \mathrm{NPs}$. Additionally, an artificial aging procedure (thermocycling) was conducted to simulate 1 year of clinical use. However, the analysis was limited in that it evaluated the specimens in settings that differ from the oral cavity environment with regard to alterations in temperature and $\mathrm{pH}$ and the absence of natural saliva, which contains a variety of species of microorganisms. Nanoparticlemodified denture base material displayed improved physical and mechanical properties in the present study, but further research investigating the addition of nanoparticles to computer-aided design and computer-aided manufacturing (CAD/CAM) prepolymerized disks should be performed in order to solidify this method as a promising technique [37].

\section{Conclusions}

Despite the limitations of the present analysis, we reached the following conclusions:

(1) The incorporation of $\mathrm{ZrO}_{2} \mathrm{NPs}$ into heat-polymerized acrylic resin decreased C. albicans adhesion and conferred a long-term antifungal effect.

(2) Adding $\mathrm{ZrO}_{2} \mathrm{NPs}$ to heat-polymerized acrylic resin decreased the contact angle and increased the surface roughness; $1 \% \mathrm{ZrO}_{2} \mathrm{NPs}$ by weight were considered the most appropriate concentration.

\section{Data Availability}

The data used to support this study are available from the corresponding author upon request.

\section{Disclosure}

This research did not receive any specific grants from funding agencies in the public, commercial, or not-for-profit sectors.

\section{Conflicts of Interest}

The authors report no conflicts of interest.

\section{Acknowledgments}

The authors would like to thank Mr. Badar T. Alsaqer, Department of Microbiology, College of Medicine, Imam Abdulrahman Bin Faisal University, for his help with microbial assays.

\section{References}

[1] M. M. Harriott and M. C. Noverr, "Importance of Candidabacterial polymicrobial biofilms in disease," Trends in Microbiology, vol. 19, no. 11, pp. 557-563, 2011.

[2] L. Gendreau and Z. G. Loewy, "Epidemiology and etiology of denture stomatitis," Journal of Prosthodontics, vol. 20, no. 4, pp. 251-260, 2011.

[3] A. Gleiznys, E. Zdanavičienè, and J. Žilinskas, "Candida albicans importance to denture wearers. A literature review," Stomatologija, vol. 17, no. 2, pp. 54-66, 2015.

[4] M. Gad and S. Fouda, "Current perspectives and the future of Candida albicans-associated denture stomatitis treatment," Dental and Medical Problems, vol. 57, no. 1, pp. 95-102, 2020.

[5] D. R. Radford, S. P. Sweet, S. J. Challacombe, and J. D. Walter, "Adherence of Candida albicans to denture-base materials with different surface finishes," Journal of Dentistry, vol. 26, no. 7, pp. 577-583, 1998.

[6] C. G. Pierce, A. Srinivasan, P. Uppuluri, A. K. Ramasubramanian, and J. L. López-Ribot, "Antifungal therapy with an emphasis on biofilms," Current Opinion in Pharmacology, vol. 13, no. 5, pp. 726-730, 2013.

[7] M. Dhamande, A. Pakhan, R. Thombare, and S. Ghodpage, "Evaluation of efficacy of commercial denture cleansing agents to reduce the fungal biofilm activity from heat polymerized denture acrylic resin: an in vitro study," Contemporary Clinical Dentistry, vol. 3, no. 2, pp. 168-172, 2012.

[8] N. S. Dar-Odeh, M. Al-Beyari, and O. A. Abu-Hammad, "The role of antifungal drugs in the management of denture-associated stomatitis," International Arabic Journal of Antimicrobial Agents, vol. 2, no. 1, 2012.

[9] K. Zhang, B. Ren, X. Zhou et al., "Effect of antimicrobial denture base resin on multi-species biofilm formation," International Journal of Molecular Sciences, vol. 17, no. 7, Article ID e1033, 2016.

[10] N. C. Polychronakis, G. L. Polyzois, P. E. Lagouvardos, and T. D. Papadopoulos, "Effects of cleansing methods on 3-D surface roughness, gloss and color of a polyamide denture base material," Acta Odontologica Scandinavica, vol. 73, no. 5, pp. 353-363, 2015.

[11] S. L. Jangra, K. Stalin, N. Dilbaghi et al., "Antimicrobial activity of zirconia $\left(\mathrm{ZrO}_{2}\right)$ nanoparticles and zirconium complexes," Journal of Nanoscience and Nanotechnology, vol. 12, no. 9, pp. 7105-7112, 2012.

[12] J. Jeevanandam, A. Barhoum, Y. S. Chan, A. Dufresne, and M. K. Danquah, "Review on nanoparticles and nanostructured materials: history, sources, toxicity and regulations," Beilstein Journal of Nanotechnology, vol. 9, pp. 1050-1074, 2018.

[13] S. Gowri, R. Rajiv Gandhi, and M. Sundrarajan, "Structural, optical, antibacterial and antifungal properties of zirconia nanoparticles by biobased protocol," Journal of Materials Science \& Technology, vol. 30, no. 8, pp. 782-790, 2014. 
[14] M. Gad, R. Abualsaud, A. Rahoma, A. M. Al-Thobity, K. Alabidi, and S. Akhtar, "Effect of zirconium oxide nanoparticles addition on the optical and tensile properties of polymethyl methacrylate denture base material," International Journal of Nanomedicine, vol. 13, no. 13, pp. 283-292, 2018.

[15] M. A. Ahmed and M. I. Ebrahim, "Effect of zirconium oxide nano-fillers addition on the flexural strength, fracture toughness, and hardness of heat-polymerized acrylic resin," World Journal of Nano Science and Engineering, vol. 4, no. 2, pp. 50-57, 2014.

[16] E. A. Ayaz, B. Bağış, and S. Turgut, "Effects of thermal cycling on surface roughness, hardness and flexural strength of polymethylmethacrylate and polyamide denture base resins," Journal of Applied Biomaterials \& Functional Materials, vol. 13, no. 3, pp. 280-286, 2015.

[17] C. D. S. Silva, A. L. Machado, C. D. A. L. Chaves, A. C. Pavarina, and C. E. Vergani, "Effect of thermal cycling on denture base and autopolymerizing reline resins," Journal of Applied Oral Science, vol. 21, no. 3, pp. 219-224, 2013.

[18] M. Gad, A. Rahoma, R. Abualsaud et al., "Influence of artificial aging and $\mathrm{ZrO}_{2}$ nanoparticle-reinforced repair resin on the denture repair strength," Journal of Clinical and Experimental Dentistry, vol. 12, no. 4, pp. e354-e362, 2020.

[19] M. Gad, A. M. Al-Thobity, S. Shahin, B. Alsaqer, and A. Ali, "Inhibitory effect of zirconium oxide nanoparticles on Candida albicans adhesion to repaired polymethyl methacrylate denture bases and interim removable prostheses: a new approach for denture stomatitis prevention," International Journal of Nanomedicine, vol. 12, pp. 5409-5419, 2017.

[20] S. M. Fouda, M. M. Gad, P. Ellakany et al., "The effect of nanodiamonds on Candida albicans adhesion and surface characteristics of PMMA denture base material- an in vitro study," Journal of Applied Oral Science, vol. 27, Article ID e20180779, 2019.

[21] M. Gad, A. Rahoma, A. M. Al-Thobity, and A. ArRejaie, "Influence of incorporation of $\mathrm{ZrO}_{2}$ nanoparticles on the repair strength of polymethyl methacrylate denture bases," International Journal of Nanomedicine, vol. 11, pp. 56335643, 2016.

[22] S. Murat, G. Alp, C. Alatalı, and M. Uzun, "In vitro evaluation of adhesion ofCandida albicanson CAD/CAM PMMA-based polymers," Journal of Prosthodontics, vol. 28, no. 2, pp. e873-e879, 2019.

[23] S. Giri and A. Kindo, "Evaluation of antifungal susceptibility testing in Candida isolates by Candifast and disk-diffusion method," Indian Journal of Pathology and Microbiology, vol. 57, no. 4, pp. 595-597, 2014.

[24] M. Balouiri, M. Sadiki, and S. K. Ibnsouda, "Methods for in vitro evaluating antimicrobial activity: a review," Journal of Pharmaceutical Analysis, vol. 6, no. 2, pp. 71-79, 2016.

[25] Y. Zhang, Y. Y. Chen, L. Huang et al., "The antifungal effects and mechanical properties of silver bromide/cationic polymer nano-composite-modified Poly-methyl methacrylate-based dental resin," Scientific Reports, vol. 7, no. 1, pp. 1-3, 2017.

[26] X. Wang, H.-F. Wu, Q. Kuang, R.-B. Huang, Z.-X. Xie, and L.-S. Zheng, "Shape-dependent antibacterial activities of Ag2O polyhedral particles," Langmuir, vol. 26, no. 4, pp. 2774-2778, 2010.

[27] X. Wang, F. Yang, W. Yang, and X. Yang, "A study on the antibacterial activity of one-dimensional $\mathrm{ZnO}$ nanowire arrays: effects of the orientation and plane surface," Chemical Communications, vol. 42, pp. 4419-4421, 2007.
[28] M. Mayahara, R. Kataoka, T. Arimoto et al., "Effects of surface roughness and dimorphism on the adhesion of Candida albicans to the surface of resins: scanning electron microscope analyses of mode and number of adhesions," Journal of Investigative and Clinical Dentistry, vol. 5, no. 4, pp. 307-312, 2014.

[29] P. N. Manoudis and I. Karapanagiotis, "Modification of the wettability of polymer surfaces using nanoparticles," Progress in Organic Coatings, vol. 77, no. 2, pp. 331-338, 2014.

[30] M. K. Tiwari, I. S. Bayer, G. M. Jursich, T. M. Schutzius, and C. M. Megaridis, "Highly liquid-repellent, large-area, nanostructured poly (vinylidene fluoride)/Poly (ethyl 2-cyanoacrylate) composite coatings: particle filler effects," ACS Applied Materials \& Interfaces, vol. 2, no. 4, pp. 1114-1119, 2010.

[31] M. M. Gad, R. Abualsaud, A. M. Al-Thobity, N. Z. Baba, and F. A. Al-Harbi, "Influence of addition of different nanoparticles on the surface properties of poly (methylmethacrylate) denture base material," Journal of Prosthodontics, vol. 29, no. 5, pp. 422-428, 2020.

[32] J.-H. Lee, J.-K. Jo, D.-A. Kim, K. D. Patel, H.-W. Kim, and H.-H. Lee, "Nano-graphene oxide incorporated into PMMA resin to prevent microbial adhesion," Dental Materials, vol. 34, no. 4, pp. e63-e72, 2018.

[33] Y. Yoshijima, K. Murakami, S. Kayama et al., "Effect of substrate surface hydrophobicity on the adherence of yeast and hyphalCandida," Mycoses, vol. 53, no. 3, pp. 221-226, 2010.

[34] A. Krasowska and K. Sigler, "How microorganisms use hydrophobicity and what does this mean for human needs," Frontiers in Cellular and Infection Microbiology, vol. 4112 pages, 2014.

[35] A. A. Lazarin, A. L. Machado, C. A. Zamperini, A. F. Wady, D. M. P. Spolidorio, and C. E. Vergani, "Effect of experimental photopolymerized coatings on the hydrophobicity of a denture base acrylic resin and on Candida albicans adhesion," Archives of Oral Biology, vol. 58, no. 1, pp. 1-9, 2013.

[36] M. M. Gad and R. Abualsaud, "Behavior of PMMA denture base materials containing titanium dioxide nanoparticles: a literature review," International Journal of Biomaterials, vol. 2019, no. 31, pp. 1-14, 2019.

[37] S. Pagano, G. Lombardo, S. Caponi et al., "Bio-mechanical characterization of a CAD/CAM PMMA resin for digital removable prostheses," Dental Materials, vol. 37, no. 3, pp. e118-e130, 2021. 